\section{Bushfires as a possible explanation for the chromium impregnation of the population in New-Caledonia}

\section{GAEL THERY ${ }^{1,2,3}$, FARID JUILLOT ${ }^{2}$, MAGALI DAVID ${ }^{2}$, PHILIPPE JOURAND ${ }^{4,5}$, MARC DUCOUSSO ${ }^{4}$ AND EMMANUEL FRITSCH${ }^{2}$}

${ }^{1}$ UMR 8148 CNRS-Université Paris-Saclay

${ }^{2}$ ERL IRD 206, UMR 7590 CNRS-MNHN-Sorbonne Université

${ }^{3}$ ENSG, Ecole Nationale Supérieure de Géologie

${ }^{4}$ UMR 113 IRD-CIRAD-INRAE- Université de Montpellier

${ }^{5}$ UMR 250 IRD-IFREMER-CNRS- Université de la NouvelleCalédonie-Université de la Réunion

Presenting Author: gael.thery@universite-paris-saclay.fr

Soil heating related to bushfires is suspected to participate to trace metals mobilization towards freshwater systems, where they can represent major environmental and health issues [1]. This question is of particular concern in New Caledonia where slash-and-burn practices are commonly used by the indigenous population [2] and a large health survey showed a significant impregnation of the population with trace metals [3]. Among those trace metals, chromium is especially suspected to erase from bushfires since a large set of soils from New Caledonia are enriched in this element [4,5] and recent studies demonstrated the oxidation of insoluble $\mathrm{Cr}(\mathrm{III})$ to toxic hexavalent $\mathrm{Cr}(\mathrm{VI})$ species upon heating of synthetic $\mathrm{Cr}$ (III)-doped Fe-(hydro)oxides $[6,7]$.

In the present study, surface soils from three categories (ultramafic bedrock, calcareous and volcano-sedimentary) collected across New Caledonia were studied for their capacity at releasing chromium after heating at $200,400,600^{\circ} \mathrm{C}$ for two hours, followed by chemical extractions with $\mathrm{CaCl}_{2}(0.01 \mathrm{M})$, EDTA $(0.05 \mathrm{M})$ and $\mathrm{KH}_{2} \mathrm{PO}_{4}(0.1 \mathrm{M})$. The results of the $\mathrm{CaCl}_{2}$ extraction showed a dramatic increase of chromium leachability from $400^{\circ} \mathrm{C}$ (Figure 1). Spectrophotometry analyses indicated that all chromium leached occurred as $\operatorname{Cr}(\mathrm{VI})$. Finally, the fraction of bioavailable chromium was found to highly correlate $\left(\mathrm{R}^{2}=0.97\right)$ with total hexavalent chromium (Figure 2). Fireinduced transformation of Cr-bearing soil minerals is thus suspected to be one of the main drivers of the chromium impregnation of the population in New Caledonia through transfer of leachable $\mathrm{Cr}(\mathrm{VI})$ towards freshwater, but also because of the possible assimilation of $\mathrm{Cr}(\mathrm{VI})$ by vegetables and tubers that are commonly cultivated in indigenous subsistence farming [8].

[1] Abraham et al. (2017) Total Environ., 599-600, 17401755. [2] Toussaint (2020) Forum, 30, 157-173. [3] St-Jean et al. (2018) Int., 118, 106-115. [4] Houles et al. (2018) Ecol., 76, 964-975. [5] Vincent et al. (2018) J. Soil Biol., 86, 52-62. [6] Burton et al. (2019) Pollut., 247, 618-625. [7] Burton et al. (2019) Chemosphere, 222, 440-444. [8] Thery et (2021) Environ. Pollut., in prep.

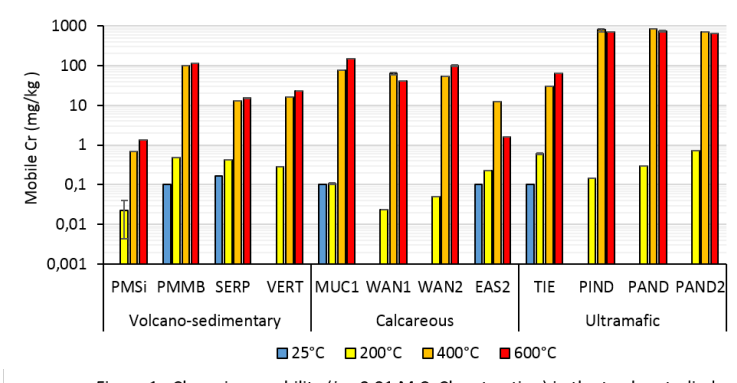

Figure 1 : Chromium mobility (i.e. $0.01 \mathrm{M} \mathrm{CaCl}_{2}$ extraction) in the twelve studied soils as a function of heating temperature.

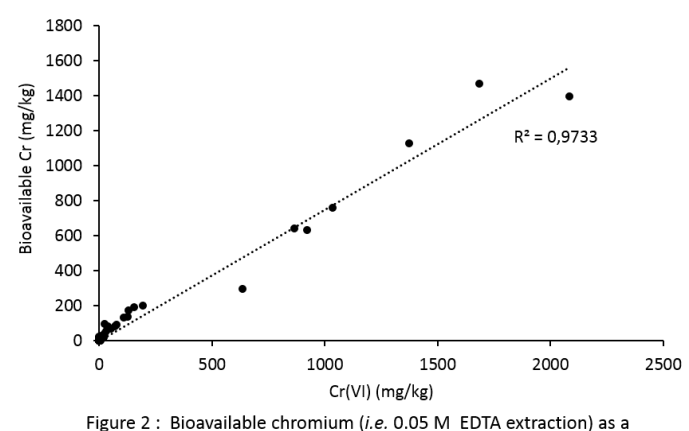
function of total hexavalent chromium (i.e. $0.1 \mathrm{M} \mathrm{KH}_{2} \mathrm{PO}_{4}$ extraction). 